\title{
LA UNIFICACIÓN DEL DERECHO COMERCIAL INTERNACIONAL: NUEVA LEX MERCATORIA COMO ALTERNATIVA AL DERECHO ESTATAL*
}

\author{
Mabel Cándano Pérez**
}

Fecha de recepción: 22 de agosto de 2017

Fecha de evaluación: 7 de diciembre de 2017

Fecha de aprobación: 22 de diciembre de 2017

Artículo de reflexión

DOI: http://dx.doi.org/10.18359/prole.3335

Forma de citación: Cándano, M. (2018). La unificación del derecho comercial internacional: nueva lex mercatoria como alternativa al derecho estatal. Revista Prolegómenos Derechos y Valores, 21, 41,149-162. DOI: http://dx.doi. org $/ 10.18359 /$ prole.3335

\section{RESUMEN}

La nueva lex mercatoria ha alcanzado un lugar en la unificación del derecho comercial internacional, para convenir la forma más justa de dirimir los conflictos entre comerciantes. Esto se refleja en un marco normativo conocido como los Principios de UNIDROIT, a pesar de la existencia de ordenamientos jurídicos en todo el mundo. En este artículo se analiza, a partir de las nuevas tendencias en el comercio internacional, las ventajas que trae consigo la figura de la lex mercatoria, como una alternativa al derecho estatal. En especial, se intenta exponer, a través de una metodología analítica, las causas, la naturaleza y los efectos de los Principios de UNIDROIT para los contratos internacionales. En consecuencia, se concluye que la concepción de esta figura se fundamenta en una elaboración detallada de un codificador privado, con términos flexibles, y su aplicación no está al margen de la intervención jurisdiccional de los Estados.

\section{Palabras clave:}

Contratos internacionales, derecho estatal, lex mercatoria, Principios de UNIDROIT.

\footnotetext{
Artículo de investigación que se enmarca dentro de los resultados del curso optativo "Principios de contratación internacional", del doctorado en Derecho de la Universidad de los Andes (Santiago de Chile, Chile).

" Abogada por la Universidad de La Habana (La Habana, Cuba), magíster en Derecho Constitucional y Administrativo por la misma institución. Magíster en Gestión de los Derechos Intelectuales por la Oficina Cubana de la Propiedad Industrial (La Habana, Cuba). Estudiante de doctorado en Derecho de la Universidad de los Andes (Santiago de Chile, Chile). Correo electrónico:mmcandano@gmail.com
} 


\title{
THE UNIFICATION OF THE INTERNATIONAL BUSINESS LAW: THE NEW LEX MERCATORIA AS A LAW ALTERNATIVE
}

\begin{abstract}
SUMMARY
The New Lex Mercatoria has gained a placed in the unification of the International Business Law to reconcile the fairest way to solve conflicts that take place between merchants. This is displayed into a legal frame known as UNIDROIT principles, even though the fact that there are several legal systems around the world. This article analyzes the advantages brought by the Lex Mercatoria from the international commerce new tendencies as an alternative to the state law. Specially, it is attempted to show through an analytic methodology the causes, nature and outcomes of the UNIDROIT principles to the international contracts. As a consequence, it is concluded that this figure conception is based onto a detailed development of a private encoder with soft terms and, its application is not set aside from the state jurisdictional intervention.
\end{abstract}

\section{Keywords:}

international contracts, state law, Lex Mercatoria, UNIDROIT principles.

\section{A UNIFICAÇÃO DO DIREITO COMERCIAL INTERNACIONAL: NOVA LEX MERCADORIA COMO ALTERNATIVA AO DIREITO ESTADUAL \\ RESUMO}

A nova lex mercatoria tem atingido um lugar na unificação do direito comercial internacional, para concordar com a maneira mais justa de resolver disputas entre comerciantes. Isso se reflete num quadro normativo conhecido como os Princípios de UNIDROIT, apesar da existência de sistemas jurídicos em todo o mundo. Neste artigo analisa-se, a partir das novas tendências no comércio internacional, as vantagens que a figura da lex mercatoria traz, como uma alternativa ao direito estadual. Em particular, tenta-se expor, através de uma metodologia analítica, as causas, a natureza e os efeitos dos Princípios de UNIDROIT para os contratos internacionais. Consequentemente, conclui-se que a concepção desta figura baseia-se numa elaboração detalhada de um codificador privado, com termos flexíveis, e a sua aplicação não está fora da intervenção jurisdicional dos Estados.

\section{Palavras chave:}

Contratos internacionais, direito estadual, lex mercatoria, Princípios de UNIDROIT.

\section{Introducción}

El derecho romano fue deficiente en la unificación del derecho comercial internacional, con el pasar del tiempo comienzan a surgir usos y costumbres concebidos por y para los comerciantes que agrupan una especie de "derecho consuetudinario y corporativo" creado por los gremios, y es la llamada lex mercatoria, la cual siempre ha sido fuente de críticas y se planteaba que no reunía los requisitos mínimos de imperatividad y precisión para ser considerada derecho.

En tal sentido, los legisladores juntaron las instituciones y elaboraron códigos nacionales, los cuales difieren entre sí en materias comerciales. Frente a esto, surge la idea de la unificación del derecho, con el fin de otorgar certeza jurídica y 
volver a la internacionalización de la lex mercatoria, mediante reglas comunes para todos los sistemas jurídicos.

Vemos cómo, en el plano internacional, las instituciones intergubernamentales o gremiales son las que han propuesto las bases para la unificación de las instituciones del derecho privado, entre ellas se destaca: la Comisión de las Naciones Unidas para el Derecho Mercantil Internacional, el Instituto Internacional para la Unificación del Derecho Privado (en adelante UNIDROIT) ${ }^{1}$ y la Cámara de Comercio Internacional (CCI).

Adviértase bien que, en las últimas décadas, se han conocido en el mundo importantes modificaciones en el volumen y en las características del comercio internacional. Hoy se observa un profundo incremento en el flujo comercial entre los Estados, aprobado, en gran medida, por el enorme desarrollo tecnológico y el perfeccionamiento de los medios de transporte y comunicación.

Por tal motivo, en este artículo se realiza un examen de la nueva lex mercatoria como derecho de los comerciantes, a la luz del derecho comercial internacional y los Principios de UNIDROIT para los contratos internacionales, teniendo en cuenta la relevancia que revisten en la interpretación de sentencias por parte de los encargados de impartir justicia y cómo se ve afectada la contratación internacional por las actuales estructuras del comercio y su dependencia al derecho estatal.

En la presente investigación, mediante el método analítico, se tuvo en consideración la revisión de fuentes documentales, la cual obedece a la revisión de la literatura teórica sobre el tema, que se encuentra publicada en libros, tesis de posgrados

UNIDROIT es una institución de carácter internacional que forma parte del conjunto de agencias formuladoras. Es un organismo creado con el fin de unificar y armonizar el derecho privado y lo hace a través de la expedición de diferentes instrumentos que tanto los Estados como los particulares pueden incorporar al ordenamiento o al contrato. Su sede principal se encuentra en Roma, Italia. Chile es parte de UNIDROIT al haber publicado su Estatuto en el Diario Oficial, el 25 de agosto de 1982, cuenta con 61 miembros. y documentos de investigación que aparecen en distintas revistas de ciencia, técnica e innovación.

Vale aclarar entonces, que una vez analizamos el nuevo escenario que surge con la figura de la lex mercatoria, como resultado de esta investigación, se logró un soporte bibliográfico, donde se evidencia que la visión cosmopolita de un derecho uniforme que ya se percibía y se pretendía en la Edad Media, sobre la base de un mercado económico supranacional, vuelve a cobrar hoy valor y a plantear la universalidad del derecho comercial internacional.

\section{A. Nuevas tendencias en el comercio internacional}

En líneas generales, un sistema de comercio internacional ha de establecer una serie de principios rectores (Ballesteros, 1977). Primero, no debe ser discriminatorio, lo cual quiere decir, que en un país no existe la discriminación entre sus interlocutores comerciales, por lo que se concede a todos, de forma igualitaria, la condición de "nación más favorecida" (Forner y Delaygua, 1988) y tampoco debe discriminar entre sus propios productos, servicios o ciudadanos y los productos, servicios o ciudadanos extranjeros, concediéndosele el "trato nacional".

Segundo, la libertad, en el sentido que las dificultades deben reducirse mediante las negociaciones y ser previsibles, ya que tanto las empresas, como los inversores y los gobiernos extranjeros, han de confiar en que no se implantarán arbitrariamente obstáculos comerciales, que incluyen los aranceles, ni tampoco, obstáculos no arancelarios y otras medidas (Ballesteros, 1977).

Tercero, el comercio deberá ser más competitivo, en cuanto a que se desalientan las prácticas "desleales" -como las subvenciones a la exportación y el dumping de productos- para ganar partes de mercado. Y un último principio es, que el comercio debe ser más ventajoso para los países menos adelantados, debiendo estos tener más tiempo para adaptarse, mayor flexibilidad y mayores privilegios (Fernández, 2000). 
No obstante, existe una nueva realidad que reporta algunos cambios. Si analizamos a los sujetos del comercio internacional, por ejemplo, dentro de esa novedad ocupa una posición destacada el Estado y las empresas multinacionales. Varían, además, los bienes susceptibles de comercio, si recordamos que ahora se comercializa software y productos industriales, a diferencia de épocas anteriores. $\mathrm{Y}$, en cuanto a la forma en que se realizan las transacciones, vemos que antes había comercio de particular a particular y ahora se empieza a desarrollar la contratación entre ausentes ${ }^{2}$.

En definitiva, se evidencia una nueva realidad del comercio internacional claramente diferenciada de la práctica comercial de años pasados. Al decir de Fernández (2000, p. 171):

[...] el sector del comercio internacional es el más afectado por la incidencia de la internacionalización de la economía, el régimen de los intercambios internacionales y la contratación internacional, el mismo queda afectado por las estructuras del comercio internacional, diseñadas, principalmente, a través de las instituciones internacionales y de la regionalización de los mercados [...].

Con todo, si se analizan las tendencias, quizá la más relevante para participar exitosamente en el comercio globalizado, sea la innovación tecnológica, que no es más que aquella capacidad para procesar información y convertirla en conocimiento útil.

En este sentido, la Organización Mundial del Comercio sostiene que las mejoras en transporte y tecnologías de la información y las telecomunicaciones, junto a la mayor integración económica y la apertura del comercio, dan lugar a una mayor difusión de la tecnología, así como a un aumento de la movilidad y de la acumulación de los factores productivos a lo largo del tiempo.

Por lo que, a través de esta tendencia, las exportaciones de los países no estarán especializadas

2 Esta contratación entre ausentes vendrá también determinada por las condiciones generales de contratación. en productos concretos, sino en la producción de bienes o componentes similares entre ellos, lo que trae como consecuencia una pérdida de importancia en la ventaja comparativa manejada por las naciones, al momento de diferenciar sus productos.

De esta manera, varios países en vías de desarrollo, caracterizados por poseer mercados pequeños, han optado por modelos de crecimiento soportados en esta tendencia, aplicada a sus exportaciones, llevándolos a la firma de acuerdos, tratados y convenios, con el propósito de incrementar la inversión extranjera directa, como por ejemplo en Cuba, con la puesta en vigor de la ley 118, Ley de la Inversión Extranjera (Consejo de Estado República de Cuba, 2014).

Dadas estas circunstancias, los volúmenes del comercio internacional han evolucionado favorablemente, se han producido cambios en la estructura de las exportaciones, ya que cada vez son más importantes los intercambios de manufacturas y servicios, que los de materias primas o productos básicos.

Por lo que han surgido también, nuevos temas prioritarios en la agenda del comercio mundial. Entre ellos, cabe resaltar el tratamiento a las exportaciones de servicios y el respeto a los derechos de propiedad intelectual, para lograr un mayor flujo de inversiones, es decir, una adecuada legislación para proteger los registros, las marcas, las patentes, los derechos de autor, las franquicias y las denominaciones de origen.

Se incluye además, el tratamiento a las inversiones, que pretende minimizar las diferencias entre los inversionistas nacionales y los extranjeros. En el sentido que ambos deben tener iguales derechos en todos los países y de esta manera establecer un balance de divisas al momento de llevar a cabo una negociación.

A modo de resumen, podemos ver que las nuevas tendencias del comercio mundial están dadas por su rápido crecimiento, su cambio de estructura y el desarrollo tecnológico; y por la existencia de mercados más abiertos y, por ende, los consu- 
midores se encuentran mejor informados y son más exigentes. Es por ello que existe un cambio en el paradigma competitivo.

Coincidimos con De Masi (2001) en que la naturaleza de la actividad comercial implica dinamismo y a lo largo de la historia se observa una estrecha relación entre especialización, tamaño del mercado y comercio internacional. Por tal razón se estima que cuando se habla de comercio, se alude a cambio y como es un cambio acelerado y formamos parte de él, en ocasiones nos cuesta comprenderlo y hace que no actuemos en consecuencia con los nuevos tiempos.

\section{Beneficios del comercio internacional}

El comercio internacional permite que un país cuente con mayor cantidad de bienes que los que podrían producirse en aislamiento, con una dotación escasa de recursos productivos. Mientras más favorable sea la relación real de intercambio para un país, mayor será el beneficio que le traerá el comercio internacional en comparación con el que obtengan los restantes países (Mendoza, Hernández y Pérez, 2014).

Por tal motivo, se aprovecha la diversidad de las condiciones de producción de las diferentes áreas del planeta y la multiplicidad en los gustos de los consumidores, por lo que se puede sacar mejor partido de esa dotación de recursos naturales o quizá de los avances tecnológicos que tengan algunos Estados y otros no (Rodríguez, 2012). De esta forma, se obtienen unos beneficios muy superiores respecto a si esos Estados fueran autosuficientes (así se reducirían los mercados y se pondría freno al desarrollo tecnológico).

Esto se traduce en un considerable aumento de operaciones internacionales realizadas por las empresas. El fenómeno del comercio internacional ofrece tres efectos de singular valor: (i) la interdependencia en el mercado de producto, puesto que crecen las importaciones y exportaciones; (ii) la interdependencia en el mercado de trabajo, por todos los desplazamientos transfronterizos de los trabajos y profesionales; y (iii) la interdependen- cia en el mercado de capitales, es decir, ahora el dinero se invierte a escala internacional, allí donde genere más rendimientos (Honnold, 1995).

En síntesis, el comercio internacional permite una mayor movilidad de los factores de producción entre países, si se tiene en cuenta que cada uno se especializa en aquellos productos donde tiene una mayor eficiencia, lo cual posibilita utilizar mejor sus recursos productivos y elevar el nivel de vida de sus trabajadores. Se alcanza un equilibrio entre la escasez y el exceso, así como los movimientos de entrada y de salida de mercancías dan paso a la balanza en el mercado internacional.

Se plantea entonces, que un hecho de tal magnitud está obligado a proyectar las relaciones que va a tener con el derecho. Se necesita una reglamentación jurídica que regule este tráfico mercantil internacional. En tal sentido, estimamos que es válido el reconocimiento universal del principio liberal de la autonomía de la voluntad, lo que coadyuva en la formación progresiva de un derecho uniforme, que está basado en los convenios o tratados internacionales, las condiciones generales y los contratos tipo, así como en las prácticas y usos del comercio internacional.

\section{B. Principios de UNIDROIT para los contratos internacionales. Su naturaleza, funciones y propósitos básicos}

Resulta imprescindible aquí para entender la nueva lex mercatoria y el sentido de la unificación del derecho comercial, hacer referencia a los Principios de UNIDROIT sobre los contratos comerciales internacionales, en tanto su naturaleza, funciones y principios básicos.

Estos se publicaron por primera vez en $1994^{3}$ y no son más que reglas generales aplicables a los contratos mercantiles internacionales, de

\footnotetext{
Hasta ahora se han publicado tres ediciones de los Principios. La primera en 1994, la segunda en 2004 y la tercera en 2016. En cada una de ellas se amplía su contenido para incluir alguno de los aspectos de la contratación comercial internacional no regulados en las anteriores.
} 
aplicación cuando las partes del contrato hayan decidido que los mismos se rijan por estos principios (autonomía de la voluntad) o hayan acordado que sus contratos se guíen por principios generales del derecho, la lex mercatoria o expresiones semejantes.

Por ende, los Principios de UNIDROIT son lo que se suele definir en derecho internacional como soft law, esto es, instrumentos cuasilegales que por sí mismos no son vinculantes jurídicamente, por carecer de rango normativo, ya que las instituciones que los crean no tienen poder legislativo (Guarín, 2015). Solo son recomendaciones, declaraciones, principios, códigos de conducta, que emiten algunos organismos internacionales y que cada vez adquieren más relevancia en la práctica legal internacional por su creciente utilización (Principios de UNIDROIT, 2016).

En este sentido, la utilidad radica en que son reconocidos por una serie de especialistas en la materia como habituales en la práctica diaria del comercio internacional, siendo por tanto principios, usos y maneras del comercio internacional también conocidos como lex mercatoria. Estos principios y costumbres por lo común no se suelen tener en cuenta en los códigos de comercio ni en la legislación interna de los países, más enfocada en las transacciones nacionales que en las internacionales.

No obstante, tal y como se recoge en el artículo 1.4 de los Principios, estos no restringen la aplicación de normas de carácter imperativo, sean de origen nacional, internacional o supranacional, que resulten aplicables conforme a las normas pertinentes de derecho internacional privado.

Estos principios se diferencian de las leyes estatales. A modo de ejemplo se menciona lo dispuesto en la formación del contrato internacional, en cuanto a la existencia de la libertad de forma. Los Principios de UNIDROIT se limitan a disponer que "nada de lo expresado en estos principios requiere que un contrato, declaración o acto alguno deba ser celebrado o probado conforme a una forma en particular. El contrato puede ser probado por cualquier medio, incluidos los testigos" (artículo 1.2). Por otro lado, reconocen los usos y costumbres del comercio internacional. En este sentido el artículo 1.9. (2) dispone que:

[...] las partes están obligadas por cualquier uso que sea ampliamente conocido y regularmente observado en el comercio internacional por los sujetos participantes en el tráfico mercantil de que se trate, a menos que la aplicación de dicho uso sea irrazonable.

A su vez, incorporan el deber de confidencialidad, así lo consigna su artículo 2.1.16:

[...] si una de las partes proporciona información como confidencial durante el curso de las negociaciones, la otra tiene el deber de no revelarla ni utilizarla injustificadamente en provecho propio, independientemente de que con posterioridad se perfeccione o no el contrato. Cuando fuere apropiado, la responsabilidad derivada del incumplimiento de esta obligación podrá incluir una compensación basada en el beneficio recibido por la otra parte.

De igual modo, resuelven el problema de la batalla de las condiciones generales de la contratación (battle of forms). Los Principios disponen que

[...] cuando ambas partes utilizan cláusulas estándar y llegan a un acuerdo excepto en lo que se refiere a dichas cláusulas, el contrato se entenderá perfeccionado sobre la base de los términos acordados y de lo dispuesto en aquellas cláusulas estándar que sean sustancialmente comunes, a menos que una de las partes claramente indique con antelación, o que con posterioridad y sin demora injustificada informe a la contraparte, que no desea quedar obligada por dicho contrato (artículo 2.1.22).

También habría que destacar que los principios ofrecen unos estándares para regular las negociaciones previas. El artículo 2.1.15 (2) dispone que "la parte que negocia o interrumpe las negociaciones de mala fe es responsable por los daños y perjuicios causados a la otra parte". 
Es válido reconocer que los redactores de los Principios han sabido ver que los negocios transnacionales a los que se dirigen estos, están siempre en continuo perfeccionamiento y que reclaman la aplicación de reglas que se adapten a ellos con facilidad y, sobre todo, que resulten útiles y eficaces para la regulación de sus relaciones contractuales. Al decir de Oviedo (2000, p. 97):

[... en los principios de UNIDROIT se enuncian reglas que son comunes a la mayoría de los sistemas legales existentes y al mismo tiempo, se adoptan soluciones para un mayor desarrollo del tráfico internacional.

Lo anterior supone un paso adelante en el desarrollo de una nueva lex mercatoria internacional, como cuerpo autónomo del derecho.

\section{La nueva lex mercatoria. Sus ventajas como derecho de los comerciantes}

Luego del breve enunciado acerca de la lex mercatoria, resulta oportuno profundizar en el tema, debido al estrecho vínculo que tiene con el derecho mercantil internacional. Esta, no es más que un orden jurídico autónomo, independiente de los sistemas jurídicos nacionales, creado espontánea y paulatinamente por quienes se encuentran envueltos en relaciones económicas internacionales y consistente en usos y costumbres globales, precedentes arbitrales y principios como los de derecho contractual de UNIDROIT (Craig, Park y Paulsson, 2000).

Según Vicent Chuliá (2000) la lex mercatoria debe abarcar con su conceptualización las condiciones generales de contratación y los contratos tipo formulados de manera unilateral por empresas o grupos de empresas vendedoras, o pactados con las asociaciones de compradores; y además, las condiciones generales elaboradas por las organizaciones en el escenario intergubernamental o privado, que intentan refundir $y$, sobre todo, seleccionar las prácticas más justas.
Se destaca con fuerza la labor efectuada por UNIDROIT en la redacción de los principios aplicables a los contratos comerciales internacionales. Son los mismos principios quienes han incorporado su legislación al ámbito internacional como una recopilación de prácticas, mejoradas de acuerdo con las exigencias de justicia y solidaridad, que no prevalecen necesariamente en el mercado internacional, pero que son un imperativo, en tanto las desigualdades deben minimizarse a la hora de resolver un conflicto, sin atender al poder económico de las empresas en juego. Los mismos principios se autodenominan lex mercatoria en tanto resultan aplicables a los contratos con la sola referencia a esta.

En este sentido, la nueva lex mercatoria está dirigida a regular los contratos comerciales internacionales, tal como surge de la compilación cada vez más extendida en el tiempo, de los Principios de UNIDROIT, obra de juristas que, sin embargo, actúa a instancia de la ley, para juzgar los contratos en su validez, interpretación y ejecución, las cláusulas compromisorias en ellos insertas, asignan competencia a las cámaras arbitrales internacionales. Los principios de derecho que la gobiernan y los laudos arbitrales que dirimen las controversias que de ellas se derivan, no señalan la supremacía de ninguno de los derechos nacionales de nuestro tiempo: del common law sobre el civil law y mucho menos de Occidente sobre de Oriente.

Hasta hace poco la tendencia jurisprudencial era considerar inválidas las cláusulas contractuales que hicieran referencia a una lex mercatoria como normativa propia, no obstante, actualmente las admiten jueces nacionales y árbitros internacionales (Oviedo, 2000).

La lex mercatoria resuelve las cuestiones propias del comercio internacional, y su práctica ha dado lugar a un derecho de índole universal aplicable a las relaciones mercantiles y que va a nacer de esos usos o prácticas comunes de los comerciantes.

A partir de esta ley se regulan las relaciones entre esos comerciantes y dentro de un ámbito determinado. Entre sus características esenciales se encuentra la autonomía, porque estos usos 
y prácticas del comercio surgen al margen del Estado. Es por lo tanto un derecho social de una clase emergente (ius mercatorum), vinculado a la actividad profesional de la misma.

Por otro lado, se define por la uniformidad internacional: porque frente al particularismo y al pluralismo de ordenamientos, aquí luce una profunda identidad de rasgos generales dentro del tráfico mercantil, lo cual constituye la respuesta a exigencias de cambio de bienes. También por la progresividad y expansión: porque va a acceder en su ámbito a los estrechos límites territoriales de las unidades políticas existentes, y de esta manera empieza a asumir un relieve europeo.

Otro rasgo característico es el origen privado, es decir, que la fuente de la misma no está en el derecho internacional o nacional, sino en la acción normativa que producen los particulares en esos usos y costumbres elaborados por la propia sociedad o por la comunidad internacional de comerciantes. Esta comunidad se apoya en corporaciones profesionales que diseñan un derecho corporativo y que someten sus operaciones mercantiles a las condiciones generales, a los contratos tipo, pero también favorecen el empleo del arbitraje.

Broseta Pont (1991) afirma que el modelo codificador actualmente no se adecúa a las exigencias internacionales del tráfico y comercio supranacionales, a las cautelas que son necesarias frente a las sociedades multinacionales, ni a la cada vez mayor internacionalización de la lex mercatoria. También sostiene el autor que el código es contradictorio con el método de creación del derecho comunitario mediante reglamentos y directivas.

Para Calvo y Carrascosa (2006) existe una acepción tradicional o moderada de la nueva lex mercatoria y una acepción avanzada de la misma. En el primer supuesto, se concibe como un conjunto de usos, contratos-tipo, reglas de asociaciones privadas, que reglamentan algunos aspectos de la contratación internacional. Es decir, no es un orden jurídico independiente de los ordenamientos nacionales, pues debe su existencia precisamente a ellos. Los derechos nacionales no se opondrían a que los contratantes incluyan en sus contratos reglas más flexibles creadas por los mismos comerciantes. En el segundo supuesto, la lex mercatoria son prácticas creadas por los comerciantes internacionales, siendo un verdadero orden jurídico que compite con los derechos nacionales y que puede regular un contrato internacional de modo autónomo, sin el concurso del derecho estatal.

No obstante, se observan como herramientas esenciales al momento de la solución de controversias por parte de los árbitros internacionales, según Jaramillo (1998), los siguientes principios que han sido enumerados como constitutivos de la lex mercatoria:

- El Pacta sunt servanda, el contrato es ley para las partes.

- El rebus sic stantibus, los cambios sustanciales en las condiciones de contratación, pueden generar la revisión del mismo.

- La culpa in contrahendo.

- La buena fe.

- El soborno genera la nulidad o ineficacia del contrato.

- Un Estado no puede evadir sus obligaciones, negando su propia capacidad de realizar un acuerdo arbitral.

- El interés de un grupo de compañías es considerado como un todo al contratar en nombre de todas ellas.

- Una parte no puede ser exonerada de sus obligaciones en razón a sus propios actos, si estos formaban parte de sus obligaciones.

- Los tribunales están obligados a aceptar los alcances dados por las partes al contrato.

- Una parte debe actuar prontamente para exigir sus derechos, no sea que se entienda que ha renunciado a ellos.

- La falta de respuesta de la correspondencia se considera evidencia de asentimiento de sus términos (Matute, 2002). 


\section{Importancia de los Principios de UNIDROIT en la interpretación de sentencias}

Si bien las soluciones que recogen los principios no son reconocidas por todos los ordenamientos jurídicos, especialmente por el derecho civil continental, en el ámbito de la contratación internacional son con frecuencia aceptadas (Guarín, 2015). Habría que indicar en este punto que, en muchas ocasiones, los principios han servido de modelo para el legislador de un determinado Estado en la creación o modificación de su derecho interno de contratos.

Asimismo, hay que subrayar la importancia que han adquirido con el tiempo, a la hora de interpretar o complementar instrumentos internacionales de derecho uniforme del comercio internacional, por parte de jueces y tribunales (Espigares, 2016). Lo cual está dado porque recogen distintas culturas jurídicas y económicas que permiten el acceso a innovadores, de las soluciones que contribuyen a enriquecer y renovar la jurisprudencia.

Estas decisiones en las que se tienen en cuenta los principios, en muchos casos son laudos arbitrales de la $\mathrm{CCI}$, en la que ejercen su función normativa e interpretativa, pero a su vez se asimilan a la lex mercatoria y a la "justicia natural". Es oportuno señalar que los principios se aplican al contrato, siempre y cuando no intenten derogar las normas de carácter imperativo del país.

En cuanto a su forma de aplicación, podemos observar dos grandes grupos: el primero, por la elección de las partes contratantes; y el segundo, por la complementariedad con el derecho internacional o nacional, cuando las partes no hayan manifestado su intención de aplicarlos directamente en sus contratos (Guarín, 2015). En el primer caso, los contratantes señalan que el contrato se regirá por los Principios de UNIDROIT o bien usan expresiones análogas, como lex mercatoria o principios generales de la contratación o del derecho.
En el segundo, a pesar de que las partes no acuerden someterse a ellos, el juez los considera un elemento relevante para interpretar cierto precepto o para integrar un vacío normativo. Dentro de los principios más aplicados se encuentra lo dispuesto en los artículos 1.3 (carácter obligatorio del acuerdo entre las partes), 4.1, 4.2 (interpretación de la declaración escrita de una de las partes como constitutiva del aviso de terminación) y 7 (derecho a terminación del contrato).

Singular referencia cobra en este plano el trabajo hecho por UNIDROIT, en tanto permite acceder a los principios recopilados de las prácticas comerciales internacionales, y se evidencia la existencia de numerosa jurisprudencia arbitral donde se aplican dichos principios (Marella y Gélinas, 1999).

En este sentido, nos percatamos de que el aporte del arbitraje a la formación y desarrollo de la lex mercatoria resulta evidente en diferentes laudos arbitrales, los cuales se apoyan en sentencias precedentes, podemos citar los casos 9593 y 7119 de la Corte de Arbitraje Internacional (Marella y Gélinas, 1999) y el tramitado por el Tribunal Arbitral en Milán, Italia, en el año $1996^{4}$ (Oviedo, 2003).

En este aspecto, encontramos otros laudos que toman a los Principios de UNIDROIT como forma de interpretar la ley nacional (Oviedo, 2003). Tal es el ejemplo del laudo del 4 de diciembre de 1996 en Roma, donde el procedimiento a seguir por el Tribunal Arbitral era tener en cuenta los usos comerciales según las leyes nacionales, pero después se consideraron los Principios de UNIDROIT como parámetro de principios y usos

\footnotetext{
4 Este caso es un contrato de agencia comercial para la distribución de artículos de mobiliario, concluido entre una compañía italiana (como principal) y un agente en los Estados Unidos. El principal declaró finalizado el contrato ante la inejecución del agente (ausencia de resultados esperados). El agente, que era el demandante, alegó terminación injusta por parte del principal y reclamó indemnización por los daños causados. Las partes estuvieron de acuerdo en que el Tribunal Arbitral aplicara los Principios de UNIDROIT (Oviedo, 2003).
} 
del comercio internacional. Debe destacarse lo anterior, aun cuando la ley aplicable según el contrato era la italiana, y de acuerdo con esta, el tribunal debía estimar los términos del contrato y los usos del comercio (Arbitral Award, 1996).

Otro caso que puede servir de referencia, es el laudo 9797 de la Corte Internacional de Arbitraje de la CCI, de fecha 28 de julio de 2000 , donde el tribunal manifestó que los Principios de UNIDROIT son fuente fidedigna del derecho comercial internacional en el arbitraje internacional, por contener ellos en esencia una compilación de los principes directeurs que disfrutan de aceptación universal y además, son el núcleo de aquellas nociones fundamentales que son aplicadas en la práctica arbitral (International Court of Arbitration, 2000) $)^{5}$.

Por otro lado, en ocasiones observamos que hay ausencia de elección de ley en el contrato. En ese sentido, en el laudo dictado en el asunto 7375, el tribunal lo interpreta como si cada parte hubiese deseado evitar la legislación nacional de la otra parte u otra ley en general. Según Marellas y Gélinas (1999): "El contrato entonces se desnacionaliza, y se aplican los Principios generales del Derecho y los Principios de UNIDROIT en cuanto ellos puedan ser considerados como el reflejo de principios y reglas generalmente aceptados" (p. 30).

Otro grupo de decisiones arbitrales alude a la función de los principios como forma de interpretar o llenar vacíos de convenciones internacionales, como es el caso de la Convención de Viena sobre compraventa internacional, que un sector de la doctrina (Garro, 1995) se orienta a sostener que si se llegaren a encontrar vacíos en ella pueda acudirse a los Principios de UNIDROIT para regularlos (Oviedo, 2003).

$5 \quad$ Caso 9797: Andersen Consulting Business Unit Member Firms vs. Arthur Andersen Business Unit Member Firms y Andersen Worldwide Societé Cooperativé. Las partes solicitaron al tribunal decidir de conformidad con los términos del contrato, teniendo en cuenta los principios de equidad.
Como se podrá advertir, no en todos los supuestos estamos en presencia de casos resueltos en las cortes de arbitraje. En el año 2010, el Tribunal Constitucional de Colombia falló en correspondencia a los Principios de UNIDROIT. Es la demanda de inconstitucionalidad en contra del inciso primero del artículo 1616 del Código Civil de Colombia ${ }^{6}$, donde la Corte Constitucional rechazó la demanda. Al hacerlo, los jueces indicaron que no solo era la disposición en cuestión ni irracional o arbitraria, sino que se inspiraron en los criterios básicos de la justicia y la equidad contractual, y por otra parte, señalan su conformidad con importantes instrumentos internacionales como la Convención de Viena en su artículo 74 y los Principios de UNIDROIT en su artículo 7.4.4. (Guarín, 2015).

Coincidimos con Matute Morales (2004) cuando se refiere a la manera reiterada con que los árbitros en sus laudos acuden a estos principios y usos para decidir, con independencia de las prescripciones de los derechos nacionales, ofreciendo soluciones propias de la lex mercatoria, que continúa afirmándose en el plano convencional internacional, en los reglamentos de las instituciones arbitrales y acertadamente en la recopilación de estos usos a modo de principios por parte de UNIDROIT (Charpentier, 2005).

Si bien es difícil saber con exactitud cuál es el impacto real de la aplicación de los principios, ya que en la mayoría de los casos en los que son elegidos por las partes no surge controversia alguna, puede decirse, con carácter general, que son empleados por un número muy elevado de contratantes internacionales y tribunales arbitrales

6 Demanda interpuesta por Enrique Javier Correa de la Hoz, Daljaira Diazgranados Vuelvas, Arlyz Romero Pérez y Miguel Cruz contra el Estado de Colombia (2010). En un desafío de la constitucionalidad del artículo 1616 del Código Civil colombiano, según el cual, salvo en caso de dolo o negligencia grave, una parte que incumpla será responsable por el daño que había previsto o debiera haber previsto, como consecuencia de su incumplimiento, en razón de que tal limitación vulnera, entre otros, el derecho fundamental de las partes a la reparación integral (Código Civil de Colombia, 2003, ley 820). 
y estatales (Finazzi, 2011) ${ }^{7}$. Y son incontables los ejemplos a los que se podría hacer referencia.

Con base en ello, los Principios de UNIDROIT han sido apreciados desde su aparición como un paso significativo hacia la modernización del derecho de contratos, al representar una suerte de codificación privada internacional de los contratos. Por ende, constituyen sin duda un esfuerzo importante para armonizar y uniformar el derecho sustantivo aplicable a los contratos comerciales internacionales.

\section{Afectación a la contratación internacional por las estructuras del comercio}

Pese a lo expuesto hasta aquí, se repara en que el sistema del comercio internacional es el más directamente afectado por la incidencia de la internacionalización de la economía. De ahí que el régimen de los intercambios internacionales y de la contratación internacional, quede decididamente afectado por unas estructuras diseñadas, principalmente, a través de las instituciones internacionales y de regionalización de los mercados. El camino recorrido por el sistema multilateral de comercio desde los orígenes del Acuerdo General sobre Aranceles Aduaneros y Comercio (GATT), ha sido trascendente por las alteraciones cualitativas y cuantitativas que ha producido en las corrientes de intercambio.

Constituye un hecho indiscutible la dialéctica entre las normas internas y las unificadoras, pues

7 Estos principios se han utilizado como ley del contrato elegida por las partes en un $27 \%$ de los casos revisados. En la mayoría de los casos, su aplicación opera de la mano del arbitraje comercial internacional (95\%). Por su parte, en un $25 \%$ de los casos revisados, estos principios se habrían empleado para corroborar la conformidad de la ley aplicable con las exigencias del comercio internacional, tanto en laudos arbitrales (57\%) como en sentencias judiciales ( $43 \%$ del total); y en un $33 \%$ de estos casos se les habría considerado como suplemento para la interpretación del derecho nacional (laudos arbitrales: $36 \%$ y sentencias judiciales: $64 \%$ ), y en un $15 \%$ como suplemento para la interpretación del derecho uniforme (laudos arbitrales: $57 \%$ y sentencias judiciales: $43 \%$; 5 \% del total). la soberanía del Estado sigue siendo un importante freno a cualquier proyecto unificador. Una vez se ha introducido en el sistema jurídico de un Estado el derecho uniforme se convierte en derecho nacional y, por ende, sigue conservando ciertas peculiaridades, derivadas de su especial proceso de elaboración, que no responde a unos principios jurídicos únicos, sino que es el resultado de una acomodación de intereses realizada por obra de la cooperación internacional.

Dichas peculiaridades se manifestarán, como es lógico, a la hora de la interpretación de las normas comerciales. Además, una ley, por técnica que sea en apariencia, es siempre la traducción de una ideología y de unos intereses y su unidad supone una política común, lo que demanda la unidad de soberanía excluida por hipótesis (Fernández, 2001). Es por ello, la necesidad de unificar el derecho comercial internacional, pero lejos de las políticas estatales.

\section{Independencia del derecho estatal}

En tal sentido, este derecho propio de los comerciantes, visto como alternativa al derecho estatal, hace que su contenido sea de difícil verificación práctica (Pendón, 2003) y solo depende del sector comercial que esté operando.

Estos usos y prácticas se generan a través de la utilización habitual de determinados contratos tipo, de definiciones uniformes o también de decisiones arbitrales. Ello incide esencialmente en algunos ámbitos, por ejemplo: en el de la contratación internacional (Berman y Dasser, 1998).

De este modo, junto a un derecho legislado producto de la unificación de las legislaciones nacionales, opera en la práctica un derecho uniforme vivo, de producción autónoma, que nace y se desenvuelve en los propios medios profesionales del tráfico mercantil internacional, y cuya uniformidad es el reflejo de la solidaridad de los intereses que une a la sociedad internacional de comerciantes. Por lo tanto, se puede resumir que la lex mercatoria trasciende las fronteras nacionales y tiende a convertirse en un ius commune del comercio internacional. 
Por ende, ha surgido por la práctica de los comerciantes pertenecientes a diversos Estados, es decir, se ha creado una sociedad internacional de comerciantes con un derecho autónomo, nacido por esas exigencias del comercio y que se ha desarrollado con independencia de los sistemas jurídicos nacionales.

$Y$ es que la nueva lex mercatoria alude a un ordenamiento jurídico que posee esos elementos comunes con los comerciantes de aquel periodo y retorna así, de nuevo, ese derecho mercantil despolitizado con uniformidad supranacional que se realiza independientemente de la unidad política y que solo se asocia a la unidad de mercado.

Se evidencia entonces que estas normas materiales especiales para el tráfico jurídico externo de la naturaleza comercial, se pueden aplicar directamente con independencia de las normas de conflicto estatales, no obstante, esto traería algunos problemas:

Primero, se va a generar el riesgo de que a través de esos usos comerciales o de los contratos tipo y condiciones generales elaborados unilateralmente, se encubran y se protejan siempre los intereses de la parte más fuerte en la contratación mercantil internacional.

Segundo, Remiro Brotons (1997) plantea que en virtud de la juridicidad que tienen esos usos y costumbres, por ser innegable el significativo papel de la lex mercatoria, se evidencia que un número muy elevado de contratos internacionales funciona satisfactoriamente por la aplicación de una serie de reglas a las que se pliegan de forma voluntaria las partes, pero ante el juez estatal, solo tendrá vigencia en la medida en que el derecho del Estado que se trata la consienta y la tolere ${ }^{8}$.

A pesar de ello, se estima que existen supuestos que declaran que se debería obviar la aplicación de un derecho estatal, como cuando una de las partes es un Estado soberano o una entidad

8 En el caso de España, todas estas afirmaciones se traducen en que los órganos jurisdiccionales no aceptarán que la regulación de un contrato se remita genérica y globalmente a la lex mercatoria. estatal. La otra parte evita así quedar expuesta a los vaivenes de cambios normativos que pueda ir haciendo el Estado, y a su vez este no está sujeto a otro derecho nacional sino directamente a normas aceptables en el escenario internacional (Moreno, 2014). Por lo que existen diversos planteamientos donde resulta altamente inapropiado remitirse a derechos "nacionales" (Ruiz, 2004).

Etel Rapallini (2011) habla de las modalidades en que se relacionan los ordenamientos jurídicos.

Se proyecta el método de la unificación, el de la armonización, el de la coordinación, entre otros. Estimo que el de la coexistencia y adaptación, responde a la expectativa planteada al proponer que diversos ordenamientos puedan aplicarse acumulativamente y en franco diálogo (p. 114).

No obstante, para la autora entre la lex mercatoria y los ordenamientos de fuente interna o internacional no debe existir un quebranto, sino una actitud de acondicionamiento y acatamiento. Asegura López Ruiz (2007, p. 15):

[...] el problema central de la lex mercatoria no afecta tanto a su caracterización o no, como ordenamiento jurídico conforme a los paradigmas del positivismo estatalista, sino a la ausencia de un orden democrático que contemple la participación de todos los potenciales afectados y desde el que se pueda legitimar su producción normativa, es decir, el núcleo de la problematización está en la ausencia de condiciones de legitimación democrática de este derecho.

En este orden de cosas, se llega a la conclusión de que su aplicación sería perfecta si se incorpora a la codificación. Se admite, de igual forma, el carácter fragmentario y no siempre público de la misma, puesto que en muchas ocasiones estas decisiones no siempre se publican, ni son motivadas.

No se trata de escapar de la legislación nacional, como algunos piensan, sino de dar respuesta a este fenómeno que va al unísono con el desarrollo del comercio mundial y que internamente, no se le ha sabido dar respuesta. De acuerdo con 
esto, los empresarios han generado de forma espontánea su derecho profesional, por lo que ha surgido un derecho comercial unificado $y, a$ la vez, un derecho desnacionalizado.

\section{Conclusiones}

El derecho uniforme utiliza con preferencia el tratado internacional de carácter multilateral como cauce de positivización, lo cual presenta ventajas e inconvenientes. Ventajas, por proporcionar certeza sobre la materia unificada, inconvenientes, por la rigidez que toda codificación trae consigo y por las dificultades de adaptación que un texto de este tipo ofrece en cada sistema jurídico nacional (Fernández, 1996).

A su vez, tal como lo hizo la Convención de Viena, los Principios de UNIDROIT no surgen con la intención de unificar el derecho general de los contratos. Sin embargo, los legisladores nacionales los tienen en cuenta porque brindan un lenguaje común sobre el derecho de los contratos, lo que conlleva una armonización espontánea del derecho y una evolución jurídica internacional.

Es por ello que la unificación del derecho del comercio internacional se ha visto favorecida por la aparición de esta nueva lex mercatoria, por tratarse de un derecho autónomo, espontáneo y uniforme del comercio internacional, que en la medida que tiende a desconectarse de manera natural de todo ordenamiento jurídico nacional, crea una efectiva uniformidad jurídica, intentando así dar solución definitiva a los nuevos conflictos del comercio internacional.

De este modo, es imposible equiparar este derecho de los comerciantes a un derecho estatal, por considerar que se está ante un conjunto de usos y prácticas dotadas de un carácter contractual, es decir, se trata de conductas que son conocidas por sujetos que forman parte de un determinado sector comercial y esto hace que los vinculen. Queda claro entonces, que frente a lo que ocurre con las normas jurídicas estatales, la aplicación última de estos usos depende de la voluntad de las partes, en tanto que estas no digan lo contrario.
Ha surgido así en nuestro tiempo, una nueva y universal lex mercatoria que, trascendiendo las fronteras nacionales, tiende a convertirse en un ius commune del comercio internacional y se observa la inmensa aceptación de esta por parte de los árbitros, al momento de resolver los conflictos internacionales que les son presentados.

\section{Referencias}

Arbitral Award. (1996). 4 XII. Roma.

Ballesteros, J. M. (1977). Comercio internacional: igualdad jurídica, discriminación de hecho. Granada: Secretaría pública. Universidad.

Berman, H. J. \& Dasser, F. J. (1998). The "new" law merchant and the "old": sources, content, and legitimacy. En: T. E. Carbonneau (ed.). Lex mercatoria and arbitration. A discussion of the new law merchant (pp. 53-69). Londres: Juris Publishing, Kluwer International Law.

Broseta, M. (1991). Tendencias actuales del derecho mercantil. En: J. L. Soberanes (ed.). Tendencias actuales del derecho (pp. 173-184). Valencia: Fondo de Cultura Económica.

Calvo, L. A. \& Carrascosa, J. (2006). Los contratos internacionales y el mito de la nueva lex mercatoria. Estudios sobre contratación internacional. Madrid: Colex.

Charpentier, E. (2005). Les "principes" d'Unidroit: une codification de la "lex mercatoria"? Les Cahiers de Droit, 46(1-2), 193-216.

Consejo de Estado República de Cuba. (2014). Ley 118. Ley de la inversión extranjera.

Craig, L., Park, W. \& Paulsson J. (2000). International Chamber of Commerce Arbitration. Nueva York: Oceana Publications.

De Masi, K. (2001). ¿Una nueva economía? Revista Finanzas y Desarrollo, 38(2), 38-41.

Espigares, J. C. (2016). Lex mercatoria: doctrina, jurisprudencia y legislación. UMH Sapiens: Divulgación Científica, 14, 1-30.

Etel, L. (2011). Evolución del ius mercatorum como fuente del derecho internacional 
privado del comercio. Revista Anales, 8(41), 108-116.

Fernández, J. C. (1996). Consideraciones en torno a la relevancia del derecho uniforme en la regulación del tráfico privado externo. En: J. L. Iglesias (coord.). Estudios jurídicos en homenaje al profesor Aurelio Menéndez (pp. 5209-5237). Madrid: Civitas.

Fernández, J. C. (2000). El derecho del comercio internacional en el contorno de la globalización. Escriva. Revista del Colegio de Notarios del Estado de México, 5, 161-230.

Fernández, J. C. (2001). Sistema de comercio internacional. Madrid: S.L Civitas Ediciones.

Finazzi, E. (2011). The impact of the Unidroit Principles in international dispute resolution in figures. Uniform Law Review, 2911, 719-737.

Forner, I. \& Delaygua, J. J. (1988). La cláusula de la nación más favorecida. Madrid: Civitas.

Garro, A. (1995). The gap filling role of the UNIDROIT principles in international sales law: some comments on the interplay between the Principles and the CISG. Tulane Law Review, 69, 1149-1257.

Guarín, J. C. (2015). Principios UNIDROIT. Ratio Iuris, Revista de Derecho Privado, 3(1), 108-137.

Honnold, J. O. (1995). Uniform laws for international trade: early "care and feeding" for uniform growth. International Trade and Business Law Journal, (1), 1-10.

International Court of Arbitration. (2000). Case No. 9797/CK/AER/ACS. Árbitro: Guillermo Gamba Posada.

Jaramillo, J. (1998). La lex mercatoria: mito o realidad. Negocios internacionales: tendencias, contratos e instrumentos. Tercer Congreso Iberoamericano de Derecho Empresarial. Bogotá.

López, F. (2007). Notas sobre la nueva lex mercatoria, Revista de Derecho del Mercado Financiero, 1, 1- 15.
Marella, F. \& Gélinas, F. (1999). The UNIDROIT principles of international commercial contracts in ICC arbitration. ICC, International Court of Arbitration Bulletin, 10(2), 26-119.

Matute, C. (2000). El arbitraje comercial internacional. Los principios jurisprudenciales de la Cámara de Comercio Internacional. Revista de la Facultad de Derecho, 1, 1-16.

Matute, C. (2004). La lex mercatoria y los principios jurisprudenciales de la Corte de Arbitraje de la Cámara de Comercio Internacional. Anuario del Instituto de Derecho Comparado, 27, 1-46.

Mendoza, S., Hernández, J. \& Pérez, J. (2014). La importancia del comercio internacional en Latinoamérica. Revista Observatorio de la Economía Latinoamericana, 201, 1-16.

Moreno, J. A. (2014). El debate sobre el derecho no estatal y la lex mercatoria. Revista de Derecho FORSETI, 1, 74-97.

Oviedo, J. (2000). Los principios de UNIDROIT para los contratos comerciales internacionales. Revista Dikaion-Lo Justo, 16(11), 96-125.

Oviedo, J. (2003). Aplicaciones de los principios de UNIDROIT a los contratos comerciales internacionales. Criterio Jurídico, 3, 7-33.

Pendón, M. A. (2003). Propósito de los principios. En: D. Morán (coord.). Comentario a los Principios de UNIDROIT para los contratos del comercio internacional (pp. 23-53). Pamplona: Aranzadi Editorial.

Remiro, A. (1997). Derecho internacional. Madrid: McGraw-Hill.

Rodríguez, M. (2012). Reconocimiento de la lex mercatoria como normativa propia y apropiada para el comercio internacional. Revista E-mercatoria, 11(2), 45-89.

Ruiz, V. (2004). The lex mercatoria and its current relevance in international commercial arbitration. Revista DeCITA, Derecho del Comercio Internacional, Temas y Actualidades, 2, 101-125.

Vicent, F. (2000). Introducción al derecho mercantil. Valencia: Tirant lo Blanch. 